\title{
Grupo de Pesquisa em Modelagem Computacional UNIFESSPA
}

\author{
Leila Weitzel $^{1}$, Paulo Quaresma ${ }^{2}$, Armanda Ribeiro ${ }^{3}$, Michael Kevin S. F ${ }^{1}$, Priscilla \\ S. Silva ${ }^{1}$, Dilcielly Almeida Ribeiro ${ }^{1}$, Raisa Brito ${ }^{1}$, Rogério Pimentel ${ }^{1}$ \\ ${ }^{1}$ Faculdade de Computação - Universidade Federal do Sul e sudeste do Pará \\ (UFESSPA) \\ Marabá - PA - Brasil \\ ${ }^{2}$ Universidade de Évora (UEVORA), Évora - Portugal \\ ${ }^{3}$ Instituto Federal de Educação, Ciência e Tecnologia do Pará (IFPA) Campus Rural \\ Marabá - PA - Brasil \\ Leila.weitzel@gmail.com, pq@uevora.pt, \\ amanda.ribeiro@ifpa.edu.br, \{michael-ksfe, priscillagat14\}@hotmail.com, \\ \{dilciellyalmeida, raisa.britoc, rgercp\}@gmail.com.
}

\begin{abstract}
This paper describes the Computational Modeling Group researches. This group exists since 2007 but only this year joined to Educational Informatics researches.

Resumo. Este ARTIGO descreve a pesquisa do Grupo de Modelagem Computacional. O grupo de pesquisa existe desde 2007, mas apenas neste ano ingressou nas pesquisas em Informática na Educação.
\end{abstract}

\section{Informações Gerais do Grupo de Pesquisa}

Nome do Grupo: Modelagem Computacional, líder Leila Weitzel (UNIFESSPA), Colaboradores a Armanda Ribeiro (IFPA) e Paulo Quaresma (UEVORA) além dos discentes bolsistas e voluntários. O grupo de pesquisa existe desde 2007, com outra formação, mas apenas neste ano ingressou no domínio da Informática na Educação. Temos dois projetos financiados: (1) FASPESPA - Fundação Amazônia Paraense de Amparo à Pesquisa, projeto Recém-Doutor, com bolsa IC; (2) PIBIC. O segundo projeto tem como objetivo estender a ontologia OBAA, Vicari et al (2010) incluindo o contexto situacional do aluno do Curso de Licenciatura em Educação no Campo (LEC). Esse curso é realizado por meio do regime de alternância, Tempo Escola (TE) e Tempo Comunidade (TC). O TE é o momento onde as aulas e práticas educativas acontecem na universidade. O TC é o momento de pesquisa, intervenções e estudos praticadas em seu ambiente natural, ou seja, no campo. A ontologia deve considerar também as especificidades dos alunos com necessidades especiais, especialmente às de visão e audição. O primeiro projeto visa desenvolver um framework que recupere de objetos de aprendizagem contextualizados, é baseado no segundo projeto.

VICARI, Rosa Maria et al. Proposta Brasileira de Metadados para Objetos de Aprendizagem Baseados em Agentes (OBAA). 2010. Disponível em: <http://seer.ufrgs.br/renote/article/view/15257/9015>. Acesso em: 26 jun. 2013. 